\title{
DETECTION OF MARINE VESSELS BASED ON VARIATION OF DEGREE OF POLARIZATION
}

\author{
Gaurav Kumar Dashondhi ${ }^{1}$, Krishna Mohan Buddhiraju ${ }^{2}$ \\ ${ }^{1,2}$ CSRE, Indian Institute of Technology Bombay, Powai, Mumbai-400 076, INDIA \\ gauravdasondhi2013@gmail.com,bkmohan@csre.iitb.ac.in
}

Commission V, SS: Atmosphere, Ocean, Weather and Climate

KEY WORDS: Degree of polarization (DOP), Variation of degree of polarization (VD), Marine vessels, Real and complex rotation, Synthetic aperture radar (SAR), Effective DOP (DOP $)$.

\begin{abstract}
For improving security of any country, satellite images are playing vital role. Vessels detection using SAR imagery is one of the primary requirements for maritime surveillance. In this paper, the algorithm used for vessels detection has four parts. The first part includes pre-processing to reduce speckle noise, second part helps in the reduction of cross polarization by real and complex rotation of the coherency matrix, third part derives a new parameter called variation of degree of polarization (VD) and fourth one is a post processing part to connect region and fill gaps using morphological operation. The proposed algorithm is tested on ALOS PALSAR1 (space borne L band) and UAVSAR (Airborne L band) datasets and yielded promising results with a relatively few false alarms.
\end{abstract}

\section{INTRODUCTION}

Marine vessels detection is one of the important topic for the maritime surveillance. In [1], [2] the authors followed a statistical approach in which they tried to first model the sea clutter based on different distributions and then they applied an adaptive thresholding based approach by using conventional CFAR algorithm and its different variants. [3] and [4] used a notch filter based approach, to detect all the targets that are other than sea clutter. In [5] the detection of ship is enhanced in compact/hybrid polarization mode as compared to the dual mode. Authors in [6] mentioned two methods in their paper. Using the first method, Optimized degree of polarization (DOP) for each pixel could be obtained by rotating either orientation or ellipticity angle. This is a time consuming method, even though the sampling interval is $1^{\circ}$. The second method is an analytical method. It treats the problem as an optimization problem, by considering DOP as an objective function with one equality constraint. They showed optimum DOP could be obtained by solving sixth order polynomial equation.

The aim of this paper is to enhance ship detection by using DOP as a physical polarimetry descriptor. DOP is a function of only sea roughness. It is necessary to understand the importance of transmitting and receiving polarization. Different pixels will give us optimum DOP as a combination of different transmitting and receiving polarization. In this paper, an algorithm is proposed to calculate the effective DOP of real and complex rotated coherency matrix. It uses the eigenvalues of the coherency matrix to better detect vessels with less number of false alarms.

This article is organized as follows: section two explains the methodology adopted (Fig. 1). Section three presents the results and discussion of the proposed algorithm on ALOS PALSAR-1 and UAVSAR. The paper ends with a conclusion and the future work.

\section{METHEDOLOGY}

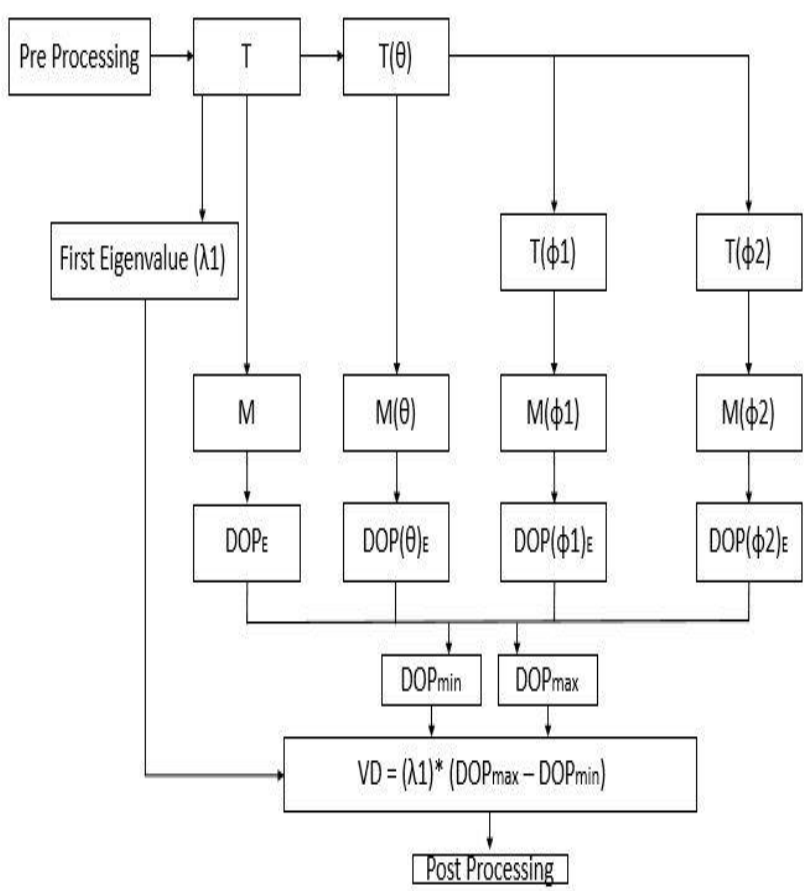

Fig. 1 Proposed Methodology Flowchart

Steps involved in proposed methodology are listed below:

Step - 1 Pre-processing

SAR images need to be pre-processed for reducing speckle noise, and in the first step, the image is filtered by $6 * 1$ multi- 
looking [7] on ALOS PALSAR-1 data to improve its interpretability of image.

\section{Step - 2 Real and complex rotation}

(2A). Coherency matrix $(\mathrm{T})-$

$$
\mathrm{T}=\left(\begin{array}{lll}
\mathrm{T}_{11} & \mathrm{~T}_{12} & \mathrm{~T}_{13} \\
\mathrm{~T}_{21} & \mathrm{~T}_{22} & \mathrm{~T}_{23} \\
\mathrm{~T}_{31} & \mathrm{~T}_{32} & \mathrm{~T}_{33}
\end{array}\right)
$$

(2B). Real rotation $(\mathrm{T}(\theta))$

$$
\begin{aligned}
& <\mathrm{T}(\theta)>=\mathrm{R}(\theta)<\mathrm{T}>\mathrm{R}(\theta)^{-1} \\
& \mathrm{R}(\theta)=\left(\begin{array}{ccc}
1 & 0 & 0 \\
0 & \cos 2 \theta & -\sin 2 \theta \\
0 & \sin 2 \theta & \cos 2 \theta
\end{array}\right) \\
& 2(\theta)=1 / 2\left(\tan ^{-1} 2 \operatorname{Re}\left(\mathrm{T}_{23}\right)\right) /\left(\mathrm{T}_{22}-\mathrm{T}_{33}\right)
\end{aligned}
$$

(2C). First complex rotation $\left(\mathrm{T}\left(\phi_{1}\right)\right)$

$$
<\mathrm{T}\left(\phi_{1}\right)>=\mathrm{R}\left(\phi_{1}\right)<\mathrm{T}(\theta)>\mathrm{R}\left(\phi_{1}\right)^{-1}
$$

$$
R\left(\phi_{1}\right)=\left(\begin{array}{ccc}
1 & 0 & 0 \\
0 & \cos 2 \phi_{1} & -\sin 2 \phi_{1} \\
0 & \mathrm{~J} \sin 2 \phi_{1} & \mathrm{~J} \cos 2 \phi_{1}
\end{array}\right)
$$$$
2\left(\phi_{1}\right)=1 / 2\left(\tan ^{-1} 2 \operatorname{lm}\left(\mathrm{T}_{22}(\theta)\right) /\left(\mathrm{T}_{22}(\theta)-\mathrm{T}_{33}(\theta)\right)\right.
$$

(2D). Second complex rotation $\left(\mathrm{T}\left(\phi_{2}\right)\right)$

$$
<\mathrm{T}\left(\phi_{2}\right)>=\mathrm{R}\left(\phi_{2}\right)<\mathrm{T}(\theta)>\mathrm{R}\left(\phi_{2}\right)^{-1}
$$$$
\mathrm{R}\left(\phi_{2}\right)=\left(\begin{array}{ccc}
\cos 2 \phi_{2} & 0 & \mathrm{~J} \sin 2 \phi_{2} \\
0 & 1 & 0 \\
\mathrm{~J} \sin 2 \phi_{2} & 0 & \cos 2 \phi_{2}
\end{array}\right)
$$$$
2\left(\phi_{2}\right)=1 / 2\left(\tan ^{-1} 2 \operatorname{lm}\left(\mathrm{T}_{22}(\theta)\right) /\left(\mathrm{T}_{22}(\theta)-\mathrm{T}_{33}(\theta)\right)\right.
$$

Real rotation $(T(\theta))$ in $2 B$, first complex rotation $\left(T\left(\phi_{1}\right)\right)$ in $2 \mathrm{C}$, and second complex rotation $\left(\mathrm{T}\left(\phi_{2}\right)\right)$ in $2 \mathrm{D}$ are subsequently performed on symmetrical Hermitian semi-definite matrix known as a coherency matrix (T) [8], [9]. It will help to reduce cross polarization, which is responsible for the overestimation of the volume scattering.

\section{Step - 3 Degree of Polarization and Muller matrix [M]}

Degree of Polarization (DOP) is a basis invariant parameter, which shows how much return is distributed in polarized component. For fully polarized wave its value is one and for unpolarised wave its value is zero, in between these two cases a partially polarised wave $(0<\mathrm{DOP}<1)$ exists.

$$
\text { DOP }=\left(\sqrt{ }\left(S^{2}{ }_{2} S^{2}{ }_{3+} S^{2}{ }_{4}\right)\right) /\left(S_{1}\right)
$$

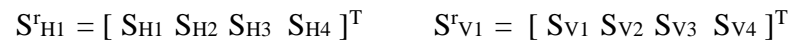

$$
\begin{aligned}
& \mathrm{S}_{\mathrm{H} 1}^{\mathrm{T}}=\left[\begin{array}{llll}
1 & 1 & 0 & 0
\end{array}\right]^{\mathrm{T}} \quad \mathrm{S}_{\mathrm{V} 1}=\left[\begin{array}{llll}
1 & -1 & 0 & 0
\end{array}\right]^{\mathrm{T}} \\
& \mathrm{DOP}_{\mathrm{H}}=\left(\sqrt{ }\left(\mathrm{S}^{2} \mathrm{H}_{2}+\mathrm{S}^{2}{ }_{\mathrm{H} 3+} \mathrm{S}^{2} \mathrm{H} 4\right)\right) /\left(\mathrm{S}_{\mathrm{H} 1}\right) \\
& \mathrm{DOP}_{\mathrm{V}}=\left(\sqrt{ }\left(\mathrm{S}^{2} \mathrm{~V} 2+\mathrm{S}^{2} \mathrm{~V} 3+\mathrm{S}^{2} \mathrm{~V} 4\right)\right) /\left(\mathrm{S}_{\mathrm{V} 1}\right) \\
& \mathrm{DOP}_{\mathrm{E}}=\sqrt{ }\left(\left(\mathrm{DOP}^{2} \mathrm{H}+\mathrm{DOP}^{2} \mathrm{v}\right) / 2\right) \\
& \mathrm{S}_{\mathrm{H} 1}^{\mathrm{r}}=[\mathrm{M}] * \mathrm{~S}^{\mathrm{T}} \mathrm{H} 1 \\
& \mathrm{~S}_{\mathrm{V} 1}=[\mathrm{M}] * \mathrm{~S}^{\mathrm{T}} \mathrm{V} 1
\end{aligned}
$$

Here $\mathrm{S}_{\mathrm{H} 1}, \mathrm{~S}_{\mathrm{V} 1}$ are horizontal, vertical received Stokes vector and $\mathrm{S}^{\mathrm{T}} \mathrm{H}_{1} \mathrm{~S}^{\mathrm{T}} \mathrm{V} 1$ are horizontal and vertical transmitted Stokes vector. Muller matrix $[\mathrm{M}][10]$ show the relationship between transmitted and received Stokes vector. Above equations, show the calculation of DOP and Effective DOP $\left(\mathrm{DOP}_{\mathrm{E}}\right)$.

\section{Step - 4 Variation of DOP (VD)}

Variation of DOP contains two parts. One part is used to calculate the difference of minimum and maximum $\mathrm{DOP}_{\mathrm{E}}$ of each pixel (it shows the range of ocean and ship "pixels). Second part uses multiplication of difference DOP with an eigenvalue of coherency matrix, for enhancing vessels pixels as compared to ocean pixels.

\section{Step - 5 Post-Processing}

The post-processing part includes the morphological operation (dilation), for filling the gaps and connecting the disconnected parts. Apart from it we determine the centroid of vessels to get the centre of the vessel.

\section{RESULTS AND DISCUSSION}

\section{3 .1 ALOS-PALSAR-1 DATA}

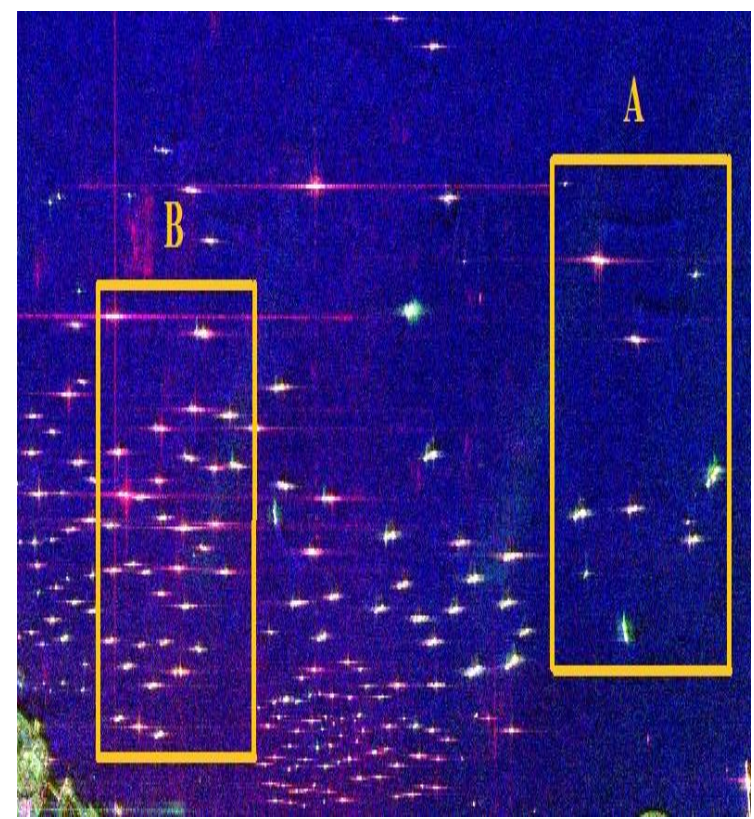

Fig. 2 ALOS PALSAR -1 Pauli RGB Image 
Table 1 ALOS-1 Input data details

\begin{tabular}{|l|l|}
\hline Parameter & Value \\
\hline Band & L Band \\
\hline Polarization & Quad (Full pol) \\
\hline Wavelength (cm) & 23 \\
\hline Resolution (m) & 9.375 \\
\hline Data Format & BSQ \\
\hline Pass & Ascending \\
\hline Range pixel spacing (m) & 3.56123 \\
\hline Azimuth pixel spacing (m) & 9.368514 \\
\hline Far look angle (degree) & 21.5 \\
\hline Incident angle (degree) & 23.97 \\
\hline Data site & Coastal area in Singapore \\
\hline Study area size & 498 X 498 \\
\hline
\end{tabular}

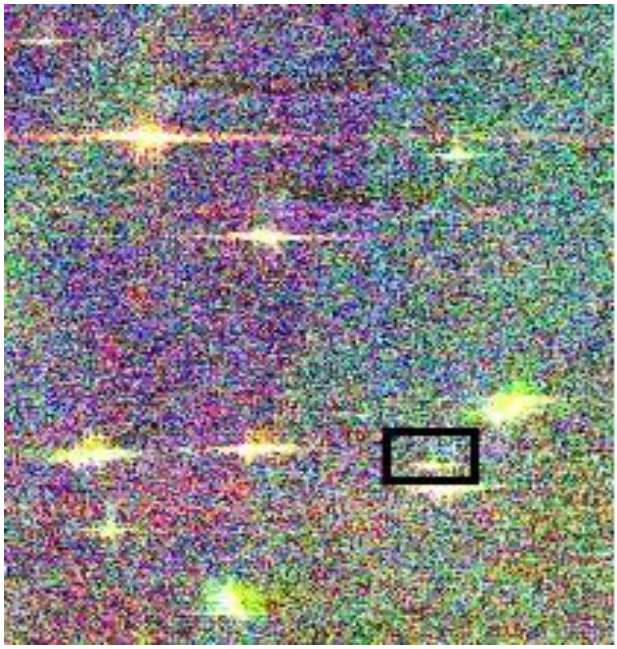

Fig. 3 ALOS PALSAR -1 sub-image A (size 235*207)

Figure 2 shows ALOS PALSAR - 1 input image. Figure 3 and 5 display the ALOS-1 sub-image A (size 235*207), B (size $209 * 165)$ respectively.

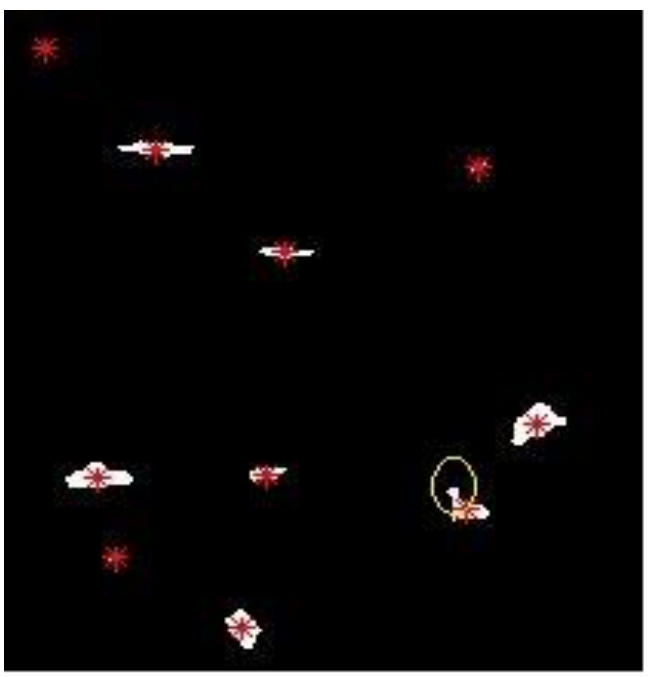

Fig. 4 ALOS PALSAR -1 sub-image A output
Table 2 ALOS-1 Vessels detection rate of Sub-image (A)

\begin{tabular}{|l|c|}
\hline Parameter & No. of Vessels \\
\hline Total vessels in input data & 11 \\
\hline Total vessels detected & 10 \\
\hline Total vessels undetected & 01 \\
\hline False Alarms & 00 \\
\hline
\end{tabular}

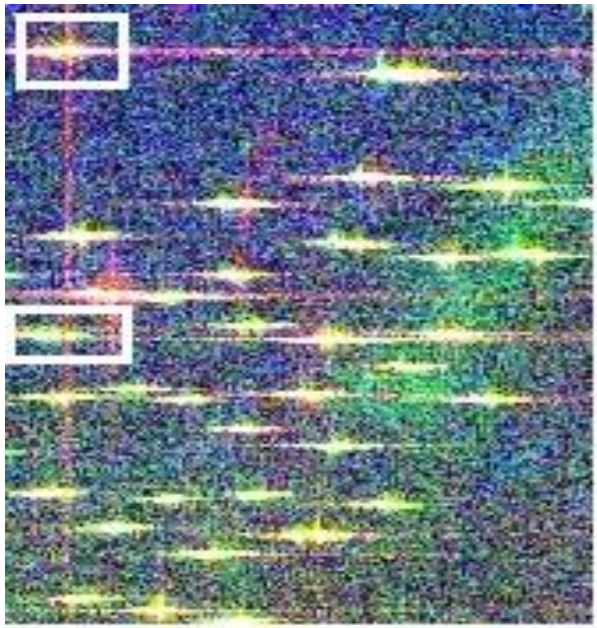

Fig. 5 ALOS PALSAR -1 sub-image B (size 209*165)

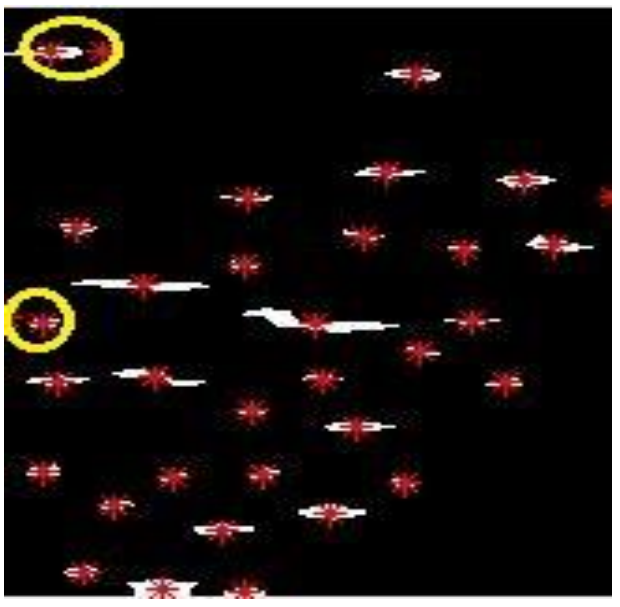

Fig. 6 ALOS PALSAR -1 sub-image B output

Table 3 ALOS-1 Vessels detection rate of Sub-image (B)

\begin{tabular}{|l|c|}
\hline Parameter & No. of Vessels \\
\hline Total vessels in input data & 33 \\
\hline Total vessels detected & 31 \\
\hline Total vessels undetected & 00 \\
\hline False Alarms & 02 \\
\hline
\end{tabular}

Figure 4, and Figure 6 show the output for sub-images of Figure 3 and 5 respectively. Figure 4, table 2 together indicate that, one vessel is undetected (Highlighted by black rectangle in Figure 3 and yellow circle in Figure 4). It is because there is very less space between these two vessels and the post-processing operation, due to which they merged and displayed as one single ship. In Figure 6, yellow circle and table 3 indicate two 
false alarms, which is due to reflection produced by vessels or we can say it happened because of echo produced by vessels.

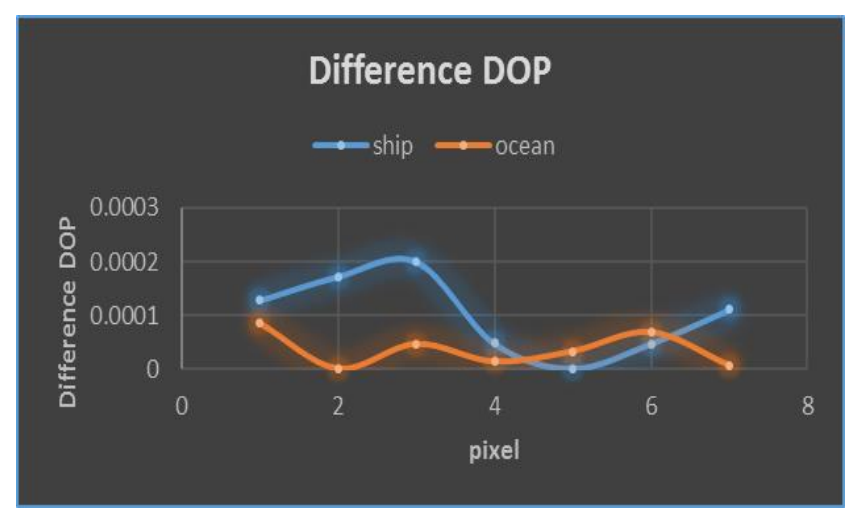

Fig. 7 ALOS1 Ship and ocean pixels [Difference of DOP] analysis

Table 4 ALOS1 Difference DOP

\begin{tabular}{|l|l|c|}
\hline No. & Ship Pixels & Ocean Pixels \\
\hline 1 & 0.000128 & $8.72 \mathrm{E}-05$ \\
\hline 2 & 0.000173 & $5.97 \mathrm{E}-07$ \\
\hline 3 & 0.000201 & $4.76 \mathrm{E}-05$ \\
\hline 4 & $4.82 \mathrm{E}-05$ & $1.38 \mathrm{E}-05$ \\
\hline 5 & $1.79 \mathrm{E}-06$ & $3.37 \mathrm{E}-05$ \\
\hline 6 & $4.78 \mathrm{E}-05$ & $7.02 \mathrm{E}-05$ \\
\hline 7 & 0.000111 & $6.8 \mathrm{E}-06$ \\
\hline
\end{tabular}

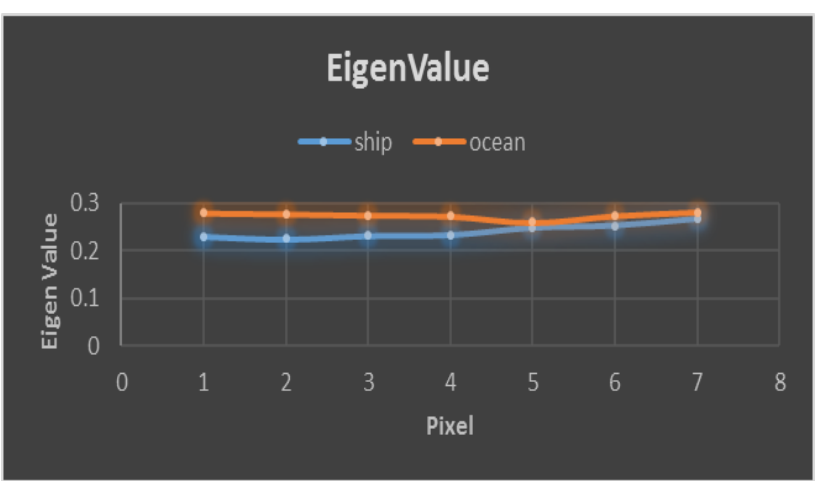

Fig. 8 ALOS1 Ship and ocean pixels [Eigenvalue] analysis

Table 5 ALOS1 Eigenvalue

\begin{tabular}{|l|l|l|}
\hline No. & Ship Pixels & Ocean pixels \\
\hline 1 & 0.230782 & 0.279218 \\
\hline 2 & 0.225227 & 0.277408 \\
\hline 3 & 0.232297 & 0.274751 \\
\hline 4 & 0.234304 & 0.2729 \\
\hline 5 & 0.248832 & 0.260147 \\
\hline 6 & 0.25321 & 0.27402 \\
\hline 7 & 0.266485 & 0.280981 \\
\hline
\end{tabular}

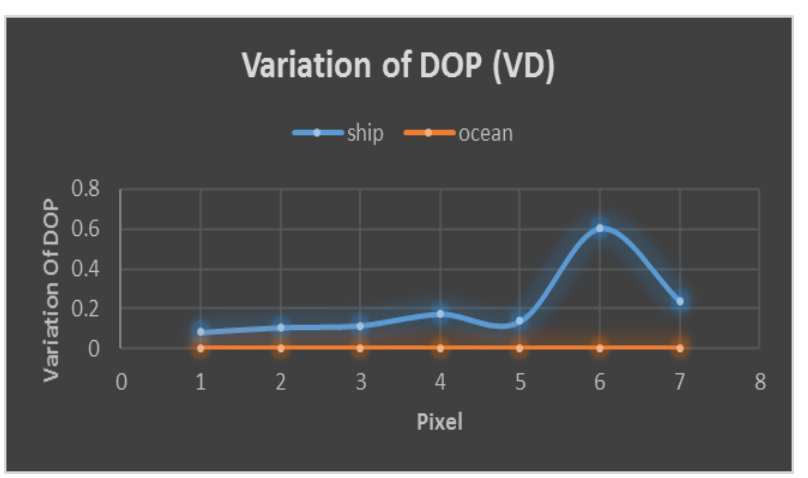

Fig. 9 ALOS1 Ship and ocean pixels [Variation of DOP] Analysis

Table 6 ALOS1 Variation of DOP (VD)

\begin{tabular}{|l|l|l|}
\hline No. & Ship pixels & Ocean pixels \\
\hline 1 & 0.082659 & $2.35 \mathrm{E}-06$ \\
\hline 2 & 0.107235 & $5.3 \mathrm{E}-06$ \\
\hline 3 & 0.116714 & $2.05 \mathrm{E}-06$ \\
\hline 4 & 0.174235 & $2.57 \mathrm{E}-05$ \\
\hline 5 & 0.137643 & $7.31 \mathrm{E}-05$ \\
\hline 6 & 0.602249 & $5.29 \mathrm{E}-05$ \\
\hline 7 & 0.238192 & $6.16 \mathrm{E}-05$ \\
\hline
\end{tabular}

Table 2 and 3 show the vessel detection rates for sub-image A, and sub-image B, which indicate how many vessels are present in input data, number of vessels detected, vessels undetected and false alarms seen in the output image. Table 4 shows the range of maximum and minimum DOP for ocean and ship pixels by taking difference between them. We can see that there is very less difference between ocean pixels among all DOP (generated by taking difference between real and complex rotated $\mathrm{T}$ matrix.) as compared to ship pixels, and figure 7 shows its analysis plot. Table 5 shows the eigenvalues corresponding to ocean and ship pixels and their analysis in figure 8 . The difference between them are very small but variation is ocean pixels are more as compared to ship pixels, which is due to differently oriented dipoles. Table 6 shows the variation of DOP (VD) for some ocean and ship pixels and its analysis show in Figure 9. we can clearly say that, the calculation of VD enables us to better distinguish between ocean and ship pixels.

\subsection{UAVSAR DATA SET}

Figure 10, 11 show a UAVSAR input image and its sub-image respectively. Table 7 contains the description of the UAVSAR input data.

Table 7 UAVSAR input data

\begin{tabular}{|l|l|}
\hline Parameter & Value \\
\hline Band & L Band \\
\hline Polarization & Quad (Full pol) \\
\hline Resolution (m) & 1.875 \\
\hline Look direction & Left \\
\hline Bandwidth & $80 \mathrm{MHz}$ \\
\hline Data site & Barro Colorado Island, Panama \\
\hline Study area size & $792 \times 1583$ \\
\hline
\end{tabular}




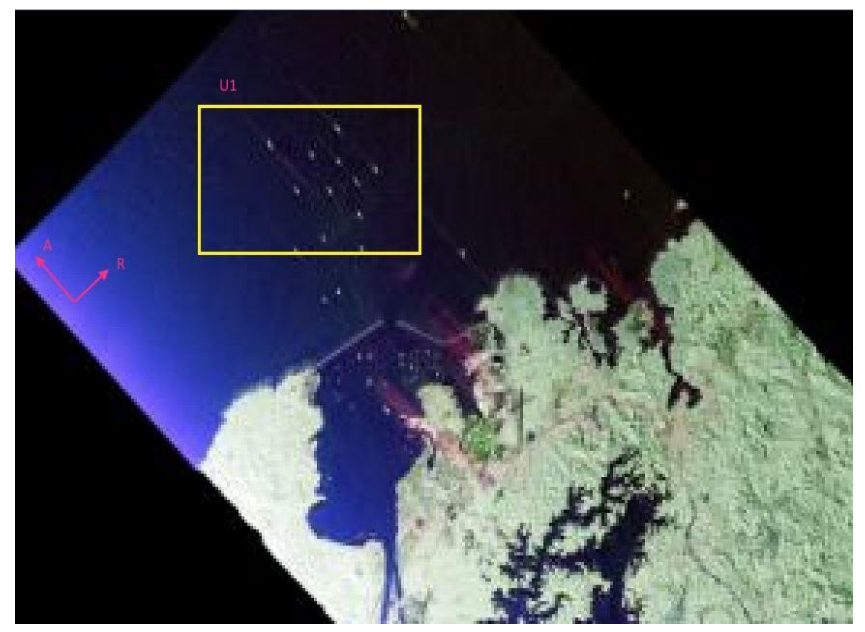

Fig. 10 UAVSAR Input Image

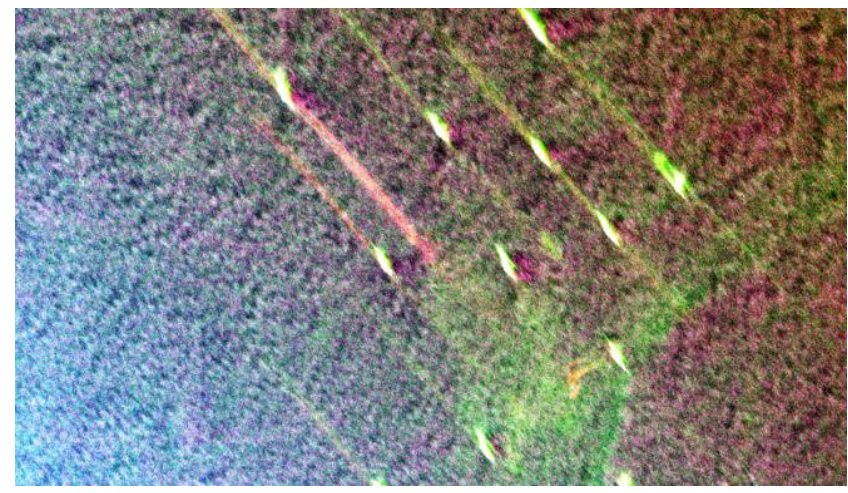

Fig. 11 UAVSAR Sub image U1 $(792 * 1583)$

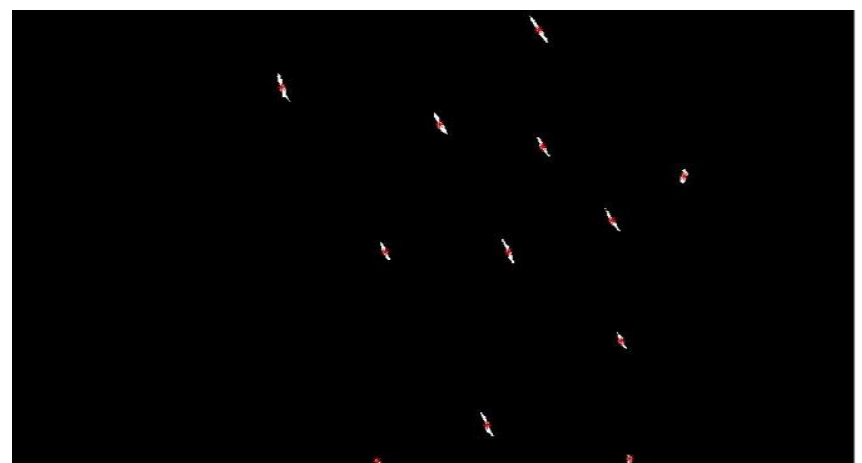

Fig. 12 UAVSAR Sub image U1 Output

Table 8 UAVSAR Vessels detection rate

\begin{tabular}{|l|l|}
\hline Parameter & No. of Vessels \\
\hline Total Vessels in Input data & 12 \\
\hline Total Vessels Detected & 12 \\
\hline Total Vessels Undetected & 0 \\
\hline False Alarm & 0 \\
\hline
\end{tabular}

Figure 12 displays the output of Sub image U1 and details about the detection rate of the algorithm on high-resolution UAVSAR image is show in table 8.
Table 9 UAVSAR Difference DOP

\begin{tabular}{|l|l|l|}
\hline No. & Ship pixels & Ocean pixels \\
\hline 1 & 2.887544 & 0.022126 \\
\hline 2 & 28.99042 & 0.032764 \\
\hline 3 & 2.420576 & 0.029262 \\
\hline 4 & 2.770918 & 0.015371 \\
\hline 5 & 50.37795 & 0.018946 \\
\hline 6 & 3.214323 & 0.020202 \\
\hline 7 & 18.71154 & 0.022153 \\
\hline
\end{tabular}

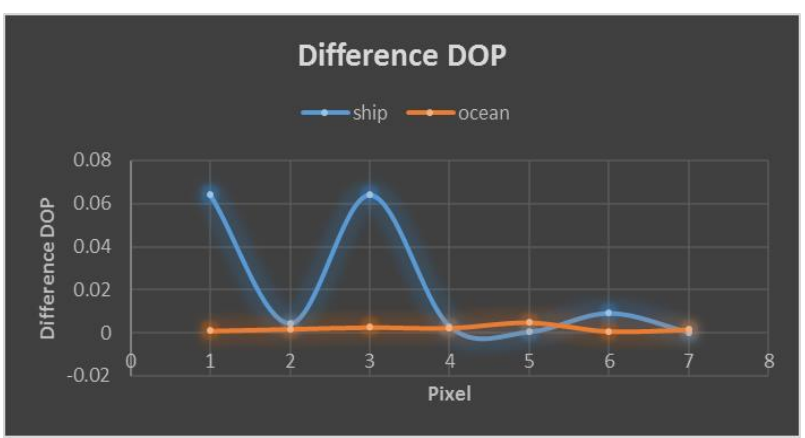

Fig. 13 UAVSAR ship and ocean pixels [Difference DOP] analysis

Table 9 shows the difference of DOP for ocean and ship pixels among the all DOP. We can see that difference between ranges of ocean pixels is not large as compared to range of ship pixels. Figure 13 shows the analysis of difference DOP for UAVSAR.

Table 10 UAVSAR Eigenvalue

\begin{tabular}{|l|l|l|}
\hline No. & Ship pixels & Ocean pixels \\
\hline 1 & 0.064399 & 0.00092 \\
\hline 2 & 0.004356 & 0.001744 \\
\hline 3 & 0.064218 & 0.002566 \\
\hline 4 & 0.002997 & 0.002248 \\
\hline 5 & 0.000385 & 0.004837 \\
\hline 6 & 0.009082 & 0.000683 \\
\hline 7 & 0.000215 & 0.001506 \\
\hline
\end{tabular}

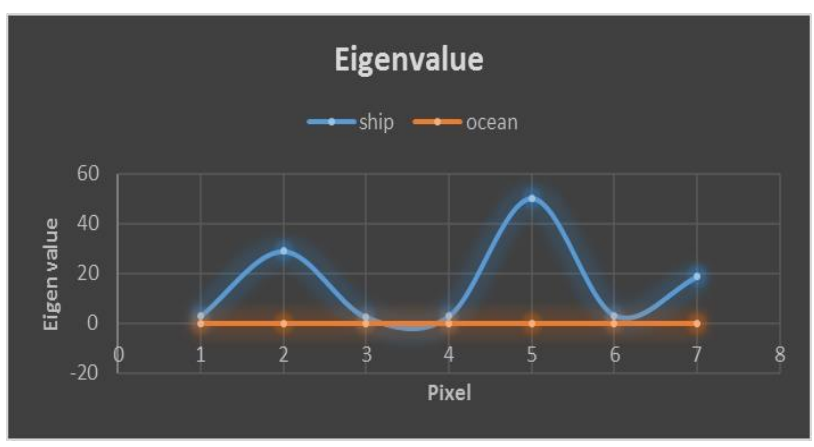

Fig. 14 UAVSAR ship and ocean pixels [Eigenvalue] analysis

Table 10 shows the eigenvalues of ship and ocean pixels. Here we can see that the values of ship pixels are higher as compared to ocean pixels, which is due to variation in the structure of ship 
pixels relative to ocean pixels. Figure 14 shows the analysis of variation in eigenvalue of ocean and ship pixels.

Table 11 UAVSAR Variation of DOP (VD)

\begin{tabular}{|l|l|l|}
\hline No. & Ship pixels & Ocean pixels \\
\hline 1 & 0.185954 & $6.86 \mathrm{E}-05$ \\
\hline 2 & 0.126273 & $4.77 \mathrm{E}-05$ \\
\hline 3 & 0.155444 & $3.01 \mathrm{E}-05$ \\
\hline 4 & 0.008305 & $8.13 \mathrm{E}-06$ \\
\hline 5 & 0.019418 & $7.63 \mathrm{E}-06$ \\
\hline 6 & 0.029193 & $6.06 \mathrm{E}-05$ \\
\hline 7 & 0.004016 & $5.53 \mathrm{E}-05$ \\
\hline
\end{tabular}

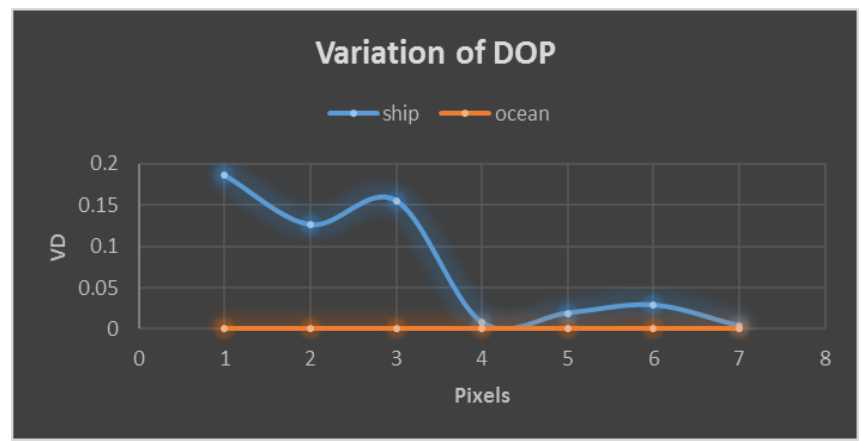

Fig. 15 Variation of DOP Analysis of UAVSAR Ship and ocean pixels

The Variation of DOP (VD) shows the separation between ocean and ship pixels, and the details are mentioned in table 11 , and figure 15 respectively.

To explain the results, it may be noted that the vessel pixels in the oceans have high DOP compared to sea pixels, but difference between them is not significant. Increase in difference between their DOP will help us to discriminate between them. Using the proposed methodology, an increase in difference between DOP of ocean and ship pixels is achieved by multiplication of the first eigenvalue of coherency matrix with the difference of minimum and maximum DOP (for vessels and ship pixels) among the real and complex rotated coherency matrix. The algorithm has nearly suppressed all ocean pixels and maintained a significant difference between ocean and ship pixels, which led us to an increase in probability of detection of vessels

\section{CONCLUSION}

In the proposed method, the Variation of Degree of Polarization (VD) is shown to be an effective discriminator to distinguish between marine vessels and the ocean surface. The methodology is being tested on a variety of SAR images, and is being extended to distinguish between floating ice blocks and ocean waters, which is a concern for safe movement of cargo vessels.

\section{ACKNOWLEDGEMENT}

Authors are greatful to UAVSAR NASA/JPL-Caltech for providing data and authors are would like to thanks JAXA for giving access to ALOS PALSAR data set.

\section{REFERENCES}

[1] M. Smith, P. Varshney, "Intelligent CFAR processor based on data variability," IEEE Transection of Aerospace Electronic System, vol. 36, no.3, pp 837-847, July 2000.

[2] Seong-In Hwang, Kauzo Ouchi, "On a novel approach using MLCC and CFAR for the improvement of ship detection by synthetic aperture radar" IEEE Geoscience and Remote Sensing Letters, vol.7, no.2, pp 391-395, April 2010.

[3] Armando Marino, "A notch filter for ship detection with polarimetry SAR data" IEEE Journal of Selected Topics in Applied Earth Observation and Remote Sensing, vol. 6, no. 3, pp 1219 -1232, March 2013.

[4] Armando Marino, Irena Hajnesk, "Statistical tests for a ship detector based on the polarimetry notch filter" IEEE Trans. on Geosci. and Remote Sens., vol. 53, no. 8, pp 4578-4595, August 2015.

[5] Reza Shirvany, Marie Chabert, Jean-Yves Tourneret "Estimation of degree of polarization for hybrid/compact and linear Dual-Pol SAR intensity images: principles and applications", IEEE Trans. on Geosci. and Remote Sens., vol. 51, no.1, pp. 539-551, July 2012.

[6] Ridha Touzi, Jeff Hurley and Paris W. Vachon, "Optimization of degree of polarization for enhanced ship detection using RADARSAT-2", IEEE Transection on Geosci. and Remote Sens., vol. 53, no. 10, pp. 54035424, June 2015.

[7] Andreas Schmitt "Multiscale and Multidirectional Multilooking for SAR Image Enhancement", IEEE Trans. on Geosci. and Remote Sens., vol. 54, no. 10, pp. $5117-$ 5134, May 2016.

[8] Avik Bhattacharya and Gulab Singh, "An adaptive general four component scattering power decomposition with unitary transformation of coherency matrix", IEEE Geoscience and Remote Sensing Letters, vol. 12, no.10, pp. $2110-2114$, July 2015.

[9] A. Bhattacharya and M. Surendar, "Enhanced target characterization and improved scattering power decomposition using the optimized coherency matrix from full polarimetric SAR data", Remote Sensing Letters, vol. 7, no.11, pp. 1073-1082, August 2016.

[10] M. Qong, T. Tadono, H. Wakabayashi and M. Shimada, "Mueller matrix based classification of polarimetric SAR data," IEEE International Geoscience and Remote Sensing Symposium. IGARSS, vol.1, pp. 375377, 2000. 